Short communication

\title{
NEW SURGICAL TECHNIQUE FOR MEDIAL PATELLAR \\ LIGAMENT SPLITTING FOR TREATMENT OF UPWARD FIXATION OF PATELLA IN CATTLE AND DONKEYS
}

\author{
M. W. EL-SHERIF \\ Department of Animal Surgery, Faculty of Veterinary Medicine, \\ Assiut University, New Valley, Egypt
}

\section{Summary}

El-Sherif, M. W., 2019. New surgical technique for medial patellar ligament splitting for treatment of upward fixation of patella in cattle and donkeys. Bulg. J. Vet. Med., 22, No 2, $243-247$.

A new medial patellar ligament splitting technique in cattle and donkeys is presented. It has been successfully applied on thirteen alive animals affected with permanent upward fixation of patella (UFP). The technique is simple, quick and easily applicable. In contrast to other medial patellar desmotomy techniques; the present approach is less invasive, the skin at the surgical site is not incised but punctured, the pericapsular fat and joint capsule are not invaded. Minimal tissue invasiveness limits the infection of surgical site, minimises bleeding and decreases their related postoperative consequences.

Key words: cattle, desmotomy, donkey, patella, upward fixation

Upward fixation of patella (UFP) has been reported with a high incidence rate in equine than in cattle (Hanson \& Peyton, 1987). This condition is believed to be due to poor conformation of the hind limb (Stick, 2006). The condition may occur temporarily, it may spontaneously recover or permanently requiring surgical correction (Lacorix, 2005). Affected animals are unable to protract the leg forward, or flex the affected limb causing the involved hind leg to drag behind. Jerky movement is observed at the walk when the MPL and its fibrocartilage disengage from the femo- ral trochlear ridge (Brooks, 2007). The condition is economically important as it reduces market value of the affected animal especially in riding animals like donkeys. Conservative treatments (Stashak, 2002; Brooks, 2007; Peitzmeier et al., 2015) were reported. Surgical treatments including medial patellar ligament desmotomy (MPLD) and ultrasound-guided medial patellar ligament splitting (MPLS) were presented (Turner \& Mcllwraith, 1989; Stashak, 2002; Tnibar, 2002; Brooks, 2007; Madhul et al., 2012; Singh et al., 2015). MPLD is usually performed 
while the animal is standing and under the effect of sedation and local anaesthesia. MPLS required general anaesthesia and animal positioned in dorsal recumbency. MPLD and MPLS are relatively invasive surgical approaches that require skin incision. Short and long term post-operative complications associated with these surgical treatments include swelling, pain, sever bleeding, wound infection and persistent low-grade lameness (Ramakrishna, 1972; Sharma, 1980; Ali \& Hashim, 1984; Tnibar, 2002). The present study presents a new surgical technique for splitting of the MPL as a surgical choice for the treatment of irresponsive upward fixation of patella in cattle and donkeys which is thought to be minimally invasive, easy and more suitable for field conditions.

The study was approved by the animal welfare committee of the Faculty of Veterinary Medicine, New Valley, Egypt. Ref. No. 1/2016.

Five donkeys (four males and one female, aged $7 \pm 2$ years and weighing $220 \pm 30 \mathrm{~kg}$ ) and eight cows (aged $4 \pm 2$ years and weighing $400 \pm 50 \mathrm{~kg}$ ) were admitted to the mobile surgery clinic of the Faculty of Veterinary Medicine, New valley, Egypt (2014-2016). They were diagnosed with permanent UFP. The donkeys and cows were sedated with xylazine hydrochloride (Xylaject, ADWIA Pharma, Egypt) at doses of $1 \mathrm{mg} / \mathrm{kg}$ (donkeys) and $0.1 \mathrm{mg} / \mathrm{kg}$ (cattle) administered intravenously.

The donkeys were secured with tying the front feet with ropes and kept in standing position while cows were positioned in lateral recumbency with the affected limb up. The stifle region of the operated limb was clipped and disinfected with absolute alcohol wipes followed by application of povidone iodine $10 \%$ solution (Betadine, Mondio, Switzerland). Ten milliliters of lidocaine hydrochloride $2 \%$ (Depocaine, Depiky pharma, Egypt) were injected underneath the skin and deep between the middle and medial patellar ligaments, about $2 \mathrm{~cm}$ above the tibial tuberosity. Further disinfection was performed with alcohol wipes and povidone iodine solution. The medial patellar ligament was located with its insertion to the tibial tuberosity then held with the tips of thumb and index fingers. Needed instruments are half circle reverse cutting needle \# 3, needle driver and silk strand (USP 1) in an appropriate length. Using aseptic technique, a sterile strand of silk mounted on a half circle reverse cutting needle is inserted through skin $2-3 \mathrm{~cm}$ above the tibial crest at the medial aspect of the medial patellar ligament (at the tip of finger) and directed underneath the ligament to emerge on the opposite side (at the tip of the other finger) between the middle and medial patellar ligaments. The two ends of the silk strand were grasped with both hands and were used to transect the ligament with sawing action movements. The sawing action was discontinued when a "POP" sound was noted, indicating completion of the desmotomy. The silk strand was then removed and surgical site disinfected again with povidone iodine solution (Fig. 1). Daily wound care with application of $10 \%$ povidone iodine antiseptic solution to the site of the procedure was performed for five successive days after surgery. Stable rest for 6 weeks was recommended. The surgical time (the time between the needle insertion and removal of silk strand from the surgical site) for each procedure was recorded. Postoperative assessment was based on daily examination of animals for lameness signs, presence of gross signs of inflammation such as "swelling, hotness, pain and redness". 

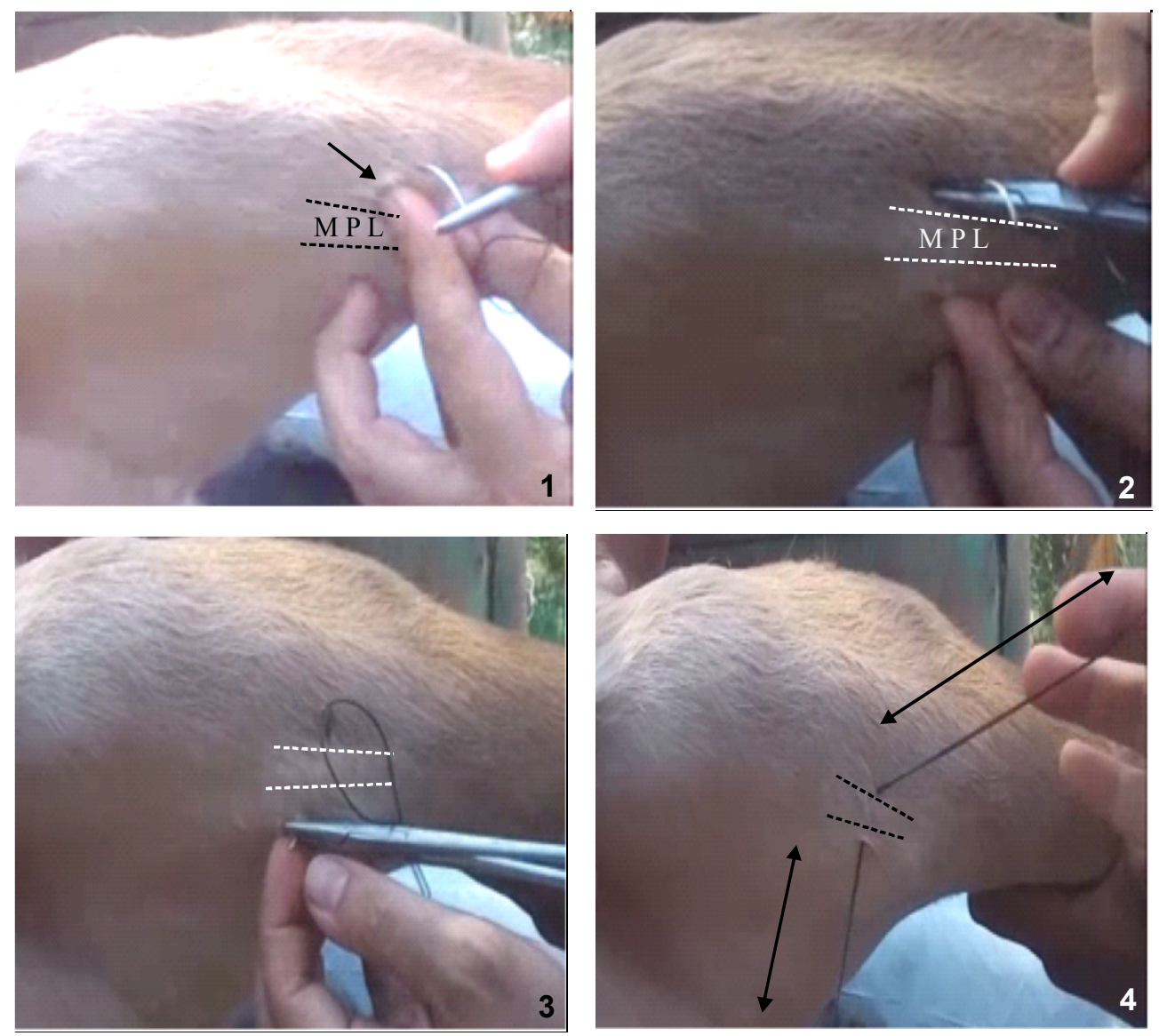

Fig. 1. The new surgical approach for medial patellar ligament splitting. The groove between the medial patellar ligament is identified with the index finger (1), a reverse sharp cutting needle with USP 1 silk thread is inserted underneath the ligament (2), the needle is advanced and emerged at the medial aspect (3), splitting of the ligament by moving the silk in sawing manner (4).

A pilot anatomical study performed on 10 donkey cadavers and bovine carcasses revealed the optimal site for the needle insertion was at the cranial aspect of the stifle, three fingers $(2-3 \mathrm{~cm})$ proximal to tibial tuberosity. This site was found to be safe due to presence of periarticular fat while, proximal to this point, it is possible to damage the superficial branch of the saphenous nerve or to penetrate the medial extension of the femoropatellar joint capsule.
The surgical procedure was technically easy to perform and no intra-operative complications were recorded. The mean surgery time was $3 \pm 1$ minutes.

Minor bleeding was noted at the points of needle insertion and exit point which stopped spontaneously. "POP" sound was heard in all cases and indicated complete transection of tensed medial patellar ligament. All treated animals regained normal posture and were able to walk normally immediately after the procedure. 
No post-operative complications were recorded over two months after the procedures in any of the treated animals. Daily examination of the animals in rest and motion revealed no signs of lameness. Minor, unnoticed scar points were present at the points of insertion and exit of the surgical needle. Signs of mild inflammation "mild swelling and redness" was noticed in one cow which subsides at the second day of the operation. Stifle of the treated animals was normal on manual palpation except for limited tissue movability which may indicate fibrosis.

The procedure presented here is a new minimal MPLS technique. It was performed successively and described in cattle and donkeys. Open and closed MPLD techniques (Ramakrishna, 1972; Sharma, 1980; Ali \& Hashim, 1984; Hanson \& Peyton, 1987; Turner \& Mcllwraith, 1989; Naveen et al., 2013) are the most commonly performed for treatment of UFP condition in large animals. Both techniques involve skin incision and stifle tissue invasion. The advantage of the present approach is the absence of skin incision, minimal tissue invasion, limited amount of surgical instrumentation needed and speed of execution.

Another technique which is the MPL splitting described by Tnibar (2002) and Andersen \& Tnibar (2016) was presented to avoid invasion of the femoro-patellar joint. The technique is more sophisticated and involves performing under general anesthesia, skin incision and percutaneous splitting the MPL with Bard Parker blade under direct visualisation of ultrasound. The present technique was easily performed in the field, performed in standing or lateral recumbent positions with minimal physical or chemical securing, didn't require special instruments and was performed under local anesthesia. The inva- sion of the femoro-patellar joint is thought not to occur. In case it occured, it was thought to be minimal. Further study should be established to evaluate the femoro-patellar joint invasion.

Incomplete severing of the ligament is a common intra-operative complication of the blind or closed technique (Ramakrishna, 1972), which necessitates several attempts to sever the ligament completely. The results of present technique showed complete transection of the medial patellar ligament in all treated animals. Bleeding, infection and swelling are common postoperative complications referred to skin incision and tissue invasion (Hanson \& Peyton, 1987; Shettko \& Trostle, 2000; Stick, 2006). The present approach was minimally tissue invasive and subsequent bleeding, infection and swelling were not noticed. The short term gross examination of treated animals showed immediate return of stifle function and absence of postoperative inflammatory signs.

Placing the animal in lateral recumbency is a disadvantage but it was recommended in cattle in order to avoid sudden movement of the animal during the procedure and as it was easier to allocate the MPL in this position. The presented technique was found to be easy, no time consuming, economic, field applicable, accurate and associated with minor postoperative complications. Further longterm study is required to evaluate this technique with the aid of more advanced diagnostic methods and tools.

\section{REFERENCES}

Ali, M. \& M. Hashim, 1984. Upward fixation of patella in cattle. Bangladesh Veterinary Journal, 18, 69-70.

Andersen, C. \& A. Tnibar, 2016. Medial patellar ligament splitting in horses with up- 
ward fixation of the patella: A long-term follow-up. Equine Veterinary Journal, $\mathbf{4 8}$, 312-314.

Brooks, J., 2007. Intermittent Upward Fixation of Patella in the Horse: A Literature Review. http://equinerehabservices.com/articles/Part-I-IUFP-OPTP.pdf (18 October 2017 date last accessed).

Hanson, R. \& L. Peyton, 1987. Surgical correction of intermittent upward fixation of patella in a Barhman cow. Canadian Veterinary Journal, 28, 675-677.

Lacorix, J., 2005. Luxation of patella. In: Lameness of the Horse. Kashvet Elearning, pp. 171-186.

Madhu, D., S. Monsang, J. Singh \& A. Pawde, 2012. Bilateral medial patellar desmotomy in a colt. Intas Polivet, 13, 264-266.

Naveen, M., D. Kumar, B. Shivaprakash, S. Usturge, A. Pawar \& N. Patil, 2013. Comparison of different methods of medial patellar desmotomy in bovines. Indian Journal of Veterinary Surgery, 34, 94-96.

Peitzmeier, M., Z. Koontz, T. Lynch, E. Hughes \& D. Slone, 2015. Outcome of medial patellar ligament desmoplasty for treatment of intermittent upward fixation of the patella in 24 horses (2005-2012). Canadian Veterinary Journal, 56, 193 195.

Ramakrishna, O., 1972. Comparative studies on treatment of chronic subluxation of the patella in buffaloes. Indian Veterinary Journal, 49, 1150-1153.

Sharma, S., 1980. Medial patellar desmotomy as treatment of stringhalt in ponies. Indian Veterinary Journal, 57, 684-685.

Shettko, D. \& S. Trostle, 2000. Diagnosis and surgical repair of patellar luxation in a flock of sheep. Journal of the American
Veterinary Medical Association, 216, 564 566.

Singh, A., A. Gangwar, K. Sangeeta \& H. Singh, 2015. Studies on incidence and evaluation of the closed medial patellar desmotomy in lateral recumbency in bovines. Veterinary World, 15, 221-224.

Stashak, T., 2002. Upward patellar fixation. In: Adam's Lameness in Horses, $5^{\text {th }}$ edn. Lippincott, Williams and Wilkins, pp. 737-741.

Stick, A., 2006. Stifle. In: Equine Surgery, $3^{\text {rd }}$ edn, Saunders Elsevier, pp. 1325-1326.

Tnibar, M., 2002. Medial patellar ligament splitting for treatment of upward fixation of the patella in seven equines. Veterinary Surgery, 31, 462-467.

Turner, A. \& C. Mcllwraith, 1989. Medial patellar desmotomy. In: Techniques in Large Animal Surgery, $2^{\text {nd }}$ edn, Lea and Febiger, pp. 133-135.

Paper received 24.06.2017; accepted for publication 21.09.2017

\section{Correspondence:}

M. W. El-Sherif

Department of Animal Surgery,

Faculty of Veterinary Medicine,

Assiut University,

New Valley, Egypt,

e-mail: drmwt@hotmail.com 